\title{
Capacidade de organização social em enfrentamentos socioambientais
}

\author{
Ricardo Almeida ${ }^{1}$ \\ http://orcid.org/0000-0002-1211-3091
}

\author{
Carlos Roberto Massao Hayashi ${ }^{2}$ \\ https://orcid.org/0000-0003-1481-5545
}

${ }^{1}$ Universidade Federal de São Carlos, Centro de Educação e Ciências Humanas, Programa de Pós-Graduação em Ciência, Tecnologia e Sociedade, São Carlos, SP, Brasil

${ }^{2}$ Universidade Federal de São Carlos, Departamento de Ciência da Informação, Programa de Pós-Graduação em Ciência, Tecnologia e Sociedade, São Carlos, SP, Brasil

\section{Capacidade de organização social em enfrentamentos socioambientais}

Resumo: Este artigo descreve as etapas de uma pesquisa social que investigou a capacidade de organização de uma comunidade, localizada em Minas Gerais - Brasil, no enfrentamento de seus problemas socioambientais. Nos moldes de uma pesquisa participante, fez-se um diagnóstico para identificar os desafios e os potenciais mais relevantes da comunidade, os quais oportunizaram intervenções envolvendo três demandas prioritárias: melhoria das ações de educação ambiental na escola, mobilização comunitária para gestão dos resíduos eletrônicos e implementação de políticas socioambientais no município. Os resultados dessas intervenções evidenciaram que os atores sociais envolvidos, embora empenhem esforços para atuar nos enfrentamentos socioambientais, não conseguem perenizar ações a ponto de concretizar transformações mais significativas na comunidade, haja vista que no cenário prevalecem fatores como: visão superficial sobre o assunto, pouca valorização da participação coletiva por parte do poder público local e fragmentação no trabalho das lideranças comunitárias, os quais desencadeiam abandono das ações e descrédito da população nas tratativas socioambientais.

Palavras-chave: Enfrentamentos socioambientais. Ciência, Tecnologia e Sociedade. Participação social. Educação ambiental. Políticas públicas.

\section{Capacity of social organization in socio-environmental confrontations}

Abstract: This article describes the stages of a social research that investigated the organizational capacity of a community, located in Minas Gerais - Brazil, in the confrontation of its socio-environmental problems. As part of a participant survey, a diagnosis was made to identify the community's most relevant challenges and potentials, which gave rise to interventions involving three priority demands: improvement of environmental education actions at school, community mobilization for electronic waste management, and implementation of socio-environmental policies in the municipality. The results of these interventions showed that the social actors involved, although they make efforts to act in socio-environmental confrontations, are not able to perpetuate actions to the point of concretizing more significant transformations in the community, given that factors such as: superficial view on the subject still prevails, little appreciation of collective participation by the local public power and fragmentation of the work of community leaders prevail in the scenario, which trigger abandonment of actions and discredit of the population in socio-environmental negotiations.

Keywords: Socio-environmental confrontations. Science, Technology and Society. Social participation. Environmental education. Public policies.

Recebido em 17.07.2019. Aprovado em 11.02.2019. Revisado em 01.04.2019

(C) O(s) Autor(es). 2020 Acesso Aberto Esta obra está licenciada sob os termos da Licença Creative Commons

Atribuição-NãoComercial 4.0 Internacional (https://creativecommons.org/licenses/by-nc/4.0/deed.pt_BR), que permite copiar, distribuir e reproduzir em qualquer meio, bem como adaptar, transformar e criar a partir deste material, desde que para fins não comerciais e que você forneça o devido crédito aos autores e a fonte, insira um link para a Licença Creative Commons e indique se mudanças foram feitas. 


\section{Introdução}

A história da existência humana revela passagens da busca pela sobrevivência e bem-estar individual e coletivo. Sabemos que nessa trajetória o homem obteve sucesso, mas também se deparou com derrotas, fazendo com que suas experiências reduzissem cada vez mais os índices de riscos, imprevistos e ameaças. Esse desejo de aprimoramento o tornava mais ávido para encontrar formas que impedissem seu fracasso ou perda de poder.

Ao longo do tempo surgiram novas formas de poder e, a partir delas, sucessivas transformações na estrutura da sociedade, sobretudo, na forma de organização civil e política. Mais tarde, com os avanços da ciência e da tecnologia essas mudanças se intensificaram ditando um novo ritmo da vida em sociedade. Embora esse movimento tenha evidenciado o grande potencial da inteligência humana, também fez surgir conflitos de ordem econômica, social e ambiental.

A partir da década de 1970 vários questionamentos emergiram acerca dos problemas instalados na relação sociedade e meio ambiente, colocando no centro das atenções o sistema produtivo. Diferentes interpretações centraram-se nos impactos socioambientais derivados da exploração da natureza, das condições de trabalho e do uso do conhecimento científico. Nesse cenário, surge com maior vigor a participação social na tentativa de mostrar a não neutralidade da ciência e da tecnologia e o poder de organização da sociedade para compor os debates e os processos de enfrentamento da crise socioambiental.

Nesse sentido, as Ciências Humanas, como campo de estudo que fomenta o pensamento crítico sobre o mundo, acolhem temáticas ambientais em suas problematizações, ampliando a interface entre ambiente e sociedade. É, pois, nesse arranjo de conhecimento que se assenta um processo repleto de demandas por análises teóricas e práticas provenientes de articulações entre o social e o natural.

Este artigo é derivado de uma pesquisa de doutorado em Ciência, Tecnologia e Sociedade (CTS) e descreve as etapas de uma investigação dedicada a compreender como os atores sociais se organizam para superar os desafios socioambientais. Para verificar essa capacidade de organização social utilizamos métodos participantes constituídos por fases de diagnóstico, mobilização e intervenção, orientados pelas seguintes questões de pesquisa: como os atores sociais articulam entre si para atuarem de forma bem-sucedida no enfrentamento de seus problemas socioambientais? O que impede e o que impulsiona os avanços para que essa rede de atores consiga lograr êxito nesses processos de enfrentamento?

Para delimitar o objeto de estudo, optamos por trabalhar com uma comunidade de composta por aproximadamente 10 mil habitantes, situada no Estado de Minas Gerais, cujo município localiza-se estrategicamente próximo a importantes polos financeiros e políticos do Brasil e apresenta uma diversidade de atores e classes sociais, fatores esses que sustentaram a escolha do campo de estudo.

Posto isso, o artigo foi estruturado em subseções que apresentam um referencial teórico que argumenta sobre a participação da sociedade nos processos de construção do conhecimento e algumas implicações epistemológicas que ajudam a compreender a relação entre o homem e o meio ambiente, assim como perspectivas de enfrentamento de problemas emergidos dessa relação. Na sequência, são delineados os procedimentos metodológicos da pesquisa, descrevendo como foi realizada a coleta de dados e as análises que oportunizaram a realização de algumas intervenções no campo de estudo. Os resultados são discutidos na seção seguinte, onde são reveladas as principais observações sobre a capacidade de organização social diante os enfrentamentos priorizados durante a pesquisa. Com base nisso, são tecidas as considerações finais que buscam responder as questões deste estudo.

\section{A participação social na construção do conhecimento}

O século XX foi marcado por grandes revoluções científicas e sociais que deram novos rumos aos modos de vida da humanidade. Nessa época, o conhecimento científico impulsionou significativas mudanças nos processos produtivos, na comunicação e nos meios de transporte, revelando ao mundo o poder imponente da ciência e da tecnologia. No entanto, se por um lado esses avanços científicos trouxeram importantes benefícios para a sociedade, por outro, fizeram surgir nefastas consequências sociais e ambientais. Ambas as situações derivam da aplicação autônoma de descobertas científicas, a exemplo das bombas nucleares que, de forma assustadora, foram detonadas sobre o Japão em 1956 (BITTAR; FERREIRA JÚNIOR, 2014).

Esse paradoxo técnico-científico além de trazer grande desconforto à sociedade civil gerou também certa desconfiança no âmbito da comunidade científica. Neder (2015) enfatiza que em meio a esse cenário de desencantamento com a ciência e a tecnologia surgiram fenômenos sociais controversos, tais como: a automação da indústria e o desemprego; o acúmulo de capital e a exclusão social; o avanço tecnológico e a degradação 
ambiental, os quais intensificaram preocupações de que a ciência perdesse sua dimensão de liberdade e criatividade na forma de produzir conhecimento, dando origem ao movimento CTS.

A partir de um olhar crítico, o campo CTS surge como espaço participativo e democrático capaz de dar voz à dimensão social, questionando as certezas colocadas como absolutas e desvelando a não neutralidade da ciência e da tecnologia (MITCHAM, 1990). Nessa perspectiva, a sociedade passa a assumir um papel importante na trajetória da construção do conhecimento, despertando para a necessidade de sua participação nos processos decisórios. Sobre isso, Gregolin et al. (2008) assinalam que as inter-relações CTS perpassam por influências dos indivíduos e requerem o uso de metodologias que viabilizem a participação dos múltiplos atores sociais nos processos que definem a inovação e as políticas públicas.

Almeida, Luz e Scatena (2017) destacam que o cenário sociopolítico atual dispõe de normativas públicas que se firmam como um dos caminhos promissores para que a sociedade conquiste seu espaço participativo e imponha com mais efetividade seu poder de atuação frente a seus desafios socioambientais. No entanto, pontuam que ainda vigora uma dicotomia entre teoria e prática que atua como barreira no desenvolvimento dessa cultura de enfrentamento. Nesse pensamento, Costa et al. (2009) entendem que essa vulnerabilidade social resiste em razão de que a participação pública ainda é vista superficialmente, não havendo oportunidades para que aconteçam questionamentos da forma como deve ser um processo participativo. Esses mesmos autores defendem que é necessário construir processos democráticos que superem a veia autoritária dominante e evidenciem as diferenças entre ser consultado, ser ouvido e ser coautor do processo.

No tocante aos dispositivos legais brasileiros que envolvem as questões socioambientais, algumas diretrizes enfatizam ações que buscam reverter a realidade de todo esse quadro, dentre elas a Política Nacional de Educação Ambiental (PNEA), o Programa de Educação Ambiental para Mobilização Social em Saneamento (PEAMSS) e a Política Nacional de Resíduos Sólidos (PNRS). Tais instrumentos coadunam com as pautas dos mais recentes debates mundiais sobre o meio ambiente, nos quais é destacada a emergência de construir modelos de cooperação mais abertos ao diálogo, envolvendo governos e sociedade civil, assim como de estabelecer maior comprometimento com dinâmicas integradas à população (ORGANIZAÇÃO DAS NAÇÕES UNIDAS, 2015).

A PNRS consiste em um importante instrumento para enfrentamento dos problemas ambientais decorrentes do manejo inadequado dos resíduos sólidos. Propõe reduzir a geração de resíduos e melhorar as práticas de descarte e destinação de materiais recicláveis e rejeitos no País. Para tanto, instituiu a responsabilidade compartilhada de fabricantes, comerciantes e cidadãos e criou metas para eliminar o uso de lixões a céu aberto, impondo regras para que o gerenciamento de resíduos sólidos sejam implementados em nível nacional, uma vez que, de acordo com o Ministério do Meio Ambiente (MMA), pouco mais da metade dos municípios brasileiros $(54,8 \%)$ possuem Plano Integrado de Resíduos Sólidos (BRASIL, 2018).

A PNEA, instituída pela Lei n. 9.795 de 1999, declara que a educação ambiental deve ser um processo permanente e contínuo, sobre o qual o poder público, as instituições de ensino e a sociedade como um todo somam esforços para atuar com ações educativas qualificadas. Com base nisso, foi idealizado o PEAMSS, que tem caráter orientador e articulador das ações de enfrentamento socioambiental com vistas a apoiar intervenções conjuntas dos atores sociais (BRASIL, 2009).

O Programa propõe a participação da sociedade para uma atuação organizada frente os desafios socioambientais e apresenta estratégias para que a mobilização comunitária, com foco no desenvolvimento de possíveis intervenções sociais, ocorra de forma gradativa e planejada. A proposta constitui-se da fase de diagnóstico participativo, cujo objetivo é identificar os problemas e os potenciais do cenário no qual se pretende atuar, seguida das fases de mobilização e intervenção sociais, que visam socializar com os membros da comunidade envolvida as informações obtidas com o diagnóstico e convidar os atores sociais para contribuírem na elaboração das intervenções e na implementação das ações de enfrentamento dos desafios priorizados.

\section{Enfrentamentos socioambientais: implicações epistemológicas e novas perspectivas}

As questões ambientais têm-se constituído de objeto de estudo para as ciências sociais, favorecendo o surgimento de novos enfoques que ajudam a compreender as transformações derivadas da relação entre sociedade e meio ambiente (FLEURY; ALMEIDA; PREMEBIDA, 2014). Nesse sentido, o resgate epistemológico dessa temática cumpre um papel importante no mapeamento dos enfrentamentos socioambientais, evidenciando conceitos relevantes de abordagens que se concentram não apenas no ser humano, mas também nos fatos sociais e na própria natureza.

Historicamente, o progresso econômico do século XX propiciou transformações importantes no mundo, mas também desencadeou rupturas significativas no contexto social. Sobre isso, Rothberg e Kerbauy (2014) 
pontuam que embora a sociologia clássica enxergasse a modernidade como algo pacífico, essas mudanças apresentavam um lado sombrio na sua relação com o meio ambiente e com o modo de vida das pessoas, abarcando variáveis como tempo e espaço. Para esses autores, o progresso e a modernização econômica impuseram uma dinâmica na vida tradicional como nunca vista antes, na qual já não havia espaço para perceber as ameaças que vinham sendo instaladas na sociedade.

Em Giddens (1994), o processo de globalização de mercado foi preponderante nessa nova configuração de tempo e espaço, uma vez que o desenvolvimento tecnológico intensificou as atividades cotidianas acelerando o ritmo de vida das pessoas, superando as barreiras geográficas e alterando de forma muito rápida a dimensão local para uma dinâmica global. Tal fenômeno ficou conhecido por modernização reflexiva, sugerindo que a vida moderna caracterizava-se por incertezas e suposições, tendo em vista que não se podia afirmar com segurança o rumo que as coisas tomariam. Essa noção de incerteza, reforçada por olhares fixos para o futuro, deu origem uma teoria que Beck (1992) denominou de sociedade de risco, a qual representou um período em que os riscos produzidos pelas indústrias foram questionados pelas instituições centrais da sociedade.

Rothberg e Kerbauy (2014) asseveram que embora as concepções de risco, trazidas por Giddens e Beck, tenham apresentado consistência em seu questionamento sobre as transformações e os limites da modernidade, elas também enfrentaram fortes críticas, uma vez que enfatizaram a ideia de que os riscos abordados por essas teorias eram tratados de forma universal, não considerando que as ameaças poderiam ser percebidas de maneira diversa por populações e indivíduos distintos, e porque seus autores teriam avaliado os impactos de maneira muito negativa, não dando lugar aos benefícios advindos da ciência e tecnologia em detrimento de um olhar caracterizado pelo fatalismo.

Ainda que predominasse um cenário fortemente dominado pelo progresso material e repleto de questionamentos sobre os riscos que esse movimento poderia trazer à sociedade, os temas relacionados aos problemas socioambientais eram pouco contemplados pelas políticas públicas da época (MARTINS, 2004). Fato esse que contribuiu para elevar o patamar de conscientização social sobre a necessidade de participação em processos de enfrentamento que contemplem novas formas de debate e de organização da sociedade, derivadas de um sistema educacional que seja capaz de produzir conhecimento científico e tecnológico em parceria com a sociedade.

Na ótica de Costa e Loureiro (2017), a educação firma-se como perspectiva promissora de enfrentamento socioambiental, haja vista que são questões eminentemente políticas e implicadas em promover a transformação da sociedade por meio da problematização da realidade.

Adeptos do pensamento freireano, esses autores apontam a Educação Ambiental como possibilidade de superação das formas de opressão, autoridade e controle.

Posto isso, os aspectos epistemológicos da Educação Ambiental reúnem diferentes percepções sobre as formas de abordagem, tipologias e enfoques direcionados aos desafios socioambientais. Assim, as atividades pedagógicas assumem diferentes concepções para introduzir a Educação Ambiental nas práticas escolares. Loureiro (2005) afirma que essa característica do campo educacional revela-se como macrotendências oriundas de debates ambientalistas, discursos políticos ou da própria tradição do ensino, de modo que, na literatura especializada, elas ganham destaque sob três enfoques: conservador, pragmático e crítico.

A vertente conservadora, também denominada de comportamentalista, constitui-se de vivências práticas apoiadas em uma pedagogia naturalista que enfatiza mais o comportamento humano que os processos históricos, não contextualizando, portanto, a realidade e nem os fatos sociais e políticos envolvidos na crise socioambiental (LOUREIRO, 2005).

A concepção pragmática revela-se principalmente na cultura ocidental, onde os padrões e as normas sociais são estabelecidos pela economia de mercado, tendo como referência a ideia de consumo sustentável, cujas práticas enfatizam, em grande medida, o uso apropriado dos recursos naturais e os processos de reciclagem (LAYRARGUES; LIMA, 2014).

A corrente crítica, na ótica de Loureiro e Layrargues (2013), direciona-se para compreensão dos problemas ambientais por meio de contextos históricos acerca das relações sociais, políticas e culturais, uma vez que prevalece nessa vertente pedagógica a noção de que não é possível conceber a crise socioambiental dissociada dos conflitos sociais, do exercício da cidadania e dos modelos de sociedade e de desenvolvimento instalados.

Aceitas essas perspectivas, tem-se que os processos participativos são determinantes para superar os desafios socioambientais, sendo a educação ambiental e as políticas públicas mecanismos que compõem, historicamente, os movimentos científicos, tecnológicos e sociais. Entretanto, com base na indagação de Souza (2001), faz-se necessário encontrar caminhos para promover a participação da sociedade na construção de políticas públicas, ainda que os espaços democráticos careçam de infraestrutura cívica e cidadã. 


\section{Aspectos metodológicos}

O presente estudo é derivado de uma pesquisa social de natureza quanti-qualitativa e abordagem participante. A primeira etapa da investigação constituiu-se de um diagnóstico participativo envolvendo os moradores da comunidade. Para coleta de dados optamos pelo uso de um questionário estruturado por quatro dimensões, formadas por temas-geradores: percepção social sobre o ambiente em que vivem; hábitos do cotidiano; interatividade com instituições que exercem determinada liderança na comunidade e; questões relacionadas à produção e destinação de resíduos. O instrumento fez uso da escala de Likert, com cinco opções de resposta preestabelecidas pontuadas de 1 a 5 , onde 1 significa a opção menos favorável e 5 a mais favorável.

Em relação aos aspectos éticos, o projeto foi previamente submetido ao Comitê de Ética em Pesquisa envolvendo seres humanos, que após avaliação emitiu parecer favorável à realização do estudo (protocolo datado de 7 de abril de 2017, identificado sob o número 2.017.436). Os dados coletados foram agrupados, mantendo-se a confidencialidade dos respondentes e todos os entrevistados receberam explicação sobre os objetivos da pesquisa, sendo que somente responderam aqueles que aceitaram participar do processo, mediante assinatura do Termo de Consentimento Livre e Esclarecido.

Para cálculo da amostra foi utilizado o processo de amostragem por conglomerados, que é uma técnica probabilística na qual as unidades amostrais são grupos de elementos (HADDAD, 2004). O tamanho da amostra foi calculado pela equação: $n=\left\{2,0\left[z^{2} p(1-p) / d^{2}\right]\right\}$, onde, $n$ é o tamanho da amostra; 2,0 é a estimativa do efeito do desenho para amostras por conglomerados; $\mathrm{z}^{2}$ corresponde ao limite de confiança de $95 \%$; p corresponde à proporção populacional, estimada em $50 \%$ ou 0,$50 ; \mathrm{d}$ é a precisão desejada, estabelecida em $10 \%$ ou 0,10 . Assim, a amostra mínima resultou em: $\mathrm{n}=192,08$. Por conseguinte, estimou-se uma proporção de perdas (h) equivalente a $10 \%$ ou 0,10 do valor de $\mathrm{n}$, utilizando a equação: $\mathrm{n}+\mathrm{h}$. Assim, definiu-se o total de 212 entrevistados.

Os dados foram tabulados em planilha eletrônica e analisados por técnicas descritivas apoiadas pelo software SPSS Statistics versão 22.0. A partir da análise de dados identificamos os pontos mais oportunos para intervenção social e realizamos uma entrevista por pauta com os atores sociais que mais se destacaram nos critérios de interatividade e liderança comunitária. Na sequência, desenvolvemos ações de intervenção em três demandas apontadas pela comunidade, nas quais utilizamos estratégias de observação, análise documental e atuação em grupos de trabalho para compreender as formas de organização instaladas na rede de atores com potencial para atuar nos enfrentamentos socioambientais diagnosticados.

\section{Resultados e Discussão}

O diagnóstico participativo, como etapa preliminar desta investigação, alcançou a amostra calculada e apresentou indicadores que evidenciaram as principais temáticas para enfrentamento na ótica da população local. A frequência dos resultados foi organizada em tendências positivas e negativas, as quais representam os potenciais e os desafios da comunidade na vertente socioambiental. À guisa de síntese, agrupamos as informações nas Tabelas 1 e 2 para destacar os pontos mais relevantes da coleta de dados.

Tabela 1 - Potenciais mais relevantes apontados pela comunidade

\begin{tabular}{lr}
\hline Indicadores com tendência positiva (potenciais) & $\begin{array}{c}\text { Avaliação (Likert): } \\
\text { Temática }\end{array}$ \\
\hline Serviço de coleta convencional do lixo domiciliar & $92 \%$ \\
Comércio local & $93 \%$ \\
Nível de Interação das escolas com a comunidade & $44 \%$ \\
Nível de Interação das igrejas com a comunidade & $54 \%$ \\
Destinação apropriada do óleo de cozinha saturado & $76 \%$ \\
\hline
\end{tabular}

Fonte: Elaborada pelos autores (2019). 
Em relação aos potenciais, verificamos que na infraestrutura prevaleceu avaliação positiva sob os serviços públicos oferecidos à comunidade, com destaque para a coleta convencional de lixo domiciliar. O comércio local foi outro item bem avaliado pelos moradores, o qual foi ratificado por outras afirmativas, dentre elas os hábitos de fazer compras nos estabelecimentos do próprio bairro.

$\mathrm{O}$ aspecto de maior desafio apresentado pelos respondentes predominou sobre a questão envolvendo resíduos eletrônicos, mostrando ser um tema ainda pouco trabalhado na comunidade ou com baixos índices de eficácia. Trata-se de um problema que se agrava ainda mais à medida que a comunidade não tem o hábito de separar e destinar apropriadamente esse tipo de material, fator observado tanto nos resultados da pesquisa social quanto na visualização in loco feita durante o percurso porta a porta para aplicação do questionário, quando foi deflagrada a prática de descarte irregular de resíduos eletrônicos nas calçadas.

Os itens que avaliaram a interatividade da comunidade com a igreja e com a escola apresentaram os melhores índices de participação social, demonstrando que essas instituições exercem sua missão agregando valor à realidade dos moradores. O que significa dizer que há uma forte tendência de que estas instituições assumem posição de maior liderança comunitária.

Finalmente, dado enfoque à destinação de resíduos, verificamos que a comunidade tende a fazer em casa a separação correta do óleo de cozinha saturado, constituindo uma atitude positiva da comunidade para o meio ambiente, tendo em vista que mais de $80 \%$ dos respondentes declararam não descartar o óleo na rede pública de esgoto, mas sim destiná-lo a algum processo de reutilização.

\section{Tabela 2 - Desafios mais relevantes apontados pela comunidade}

\begin{tabular}{|c|c|}
\hline Indicadores com tendência negativa (desafios) & $\begin{array}{r}\text { Avaliação (Likert): } \\
\text { Péssimo/Ruim ou Nunca/Quase nunca }\end{array}$ \\
\hline \multicolumn{2}{|l|}{ Temática } \\
\hline Serviço de coleta de resíduos eletrônicos & $76 \%$ \\
\hline Uso de sacolas fixas durante as compras & $62 \%$ \\
\hline Participação das empresas nos problemas da comunidade & $54 \%$ \\
\hline Comunicação entre Prefeitura Municipal e comunidade & $56 \%$ \\
\hline Destinação de resíduos orgânicos para compostagem & $78 \%$ \\
\hline Descarte correto de resíduos eletrônicos & $65 \%$ \\
\hline
\end{tabular}

Fonte: Elaborada pelos autores (2019).

Quanto aos desafios mais relevantes, a avaliação dos respondentes recaiu sobre os resíduos eletrônicos. Os moradores apontaram alto índice de insatisfação com a coleta dos materiais eletrônicos que a eles é oferecida, o que certamente influencia os hábitos irregulares de descarte desses resíduos nas ruas, conforme destacado anteriormente. Da mesma forma, a maioria da população local evidenciou que destinam os resíduos de origem orgânica como rejeito para o aterro sanitário. Ambas as questões contribuem para agravamento do panorama brasileiro sobre os resíduos sólidos, em que 46\% dos municípios ainda não possuem se quer um plano de gestão de seus resíduos (BRASIL, 2018).

Em relação aos índices de interatividade, é possível verificar que a prefeitura municipal exerce pouca interação com a comunidade, ainda que seja uma instituição de representatividade social. Os respondentes declararam que o processo de comunicação entre eles e as autoridades públicas do município não contempla o esperado pela população local, desencadeando distanciamento entre a comunidade e o poder público. Esse indicador de interatividade coaduna com uma pesquisa realizada pelo Instituto Brasileiro de Opinião Pública e Estatística, o IBOPE, que revelou o nível de confiança dos brasileiros em instituições e grupos sociais do País (Índice de Confiança Social - ICS), destacando o Corpo de Bombeiros como instituição que os brasileiros mais confiam, seguido pela igreja - $2^{\circ}$ lugar, escola pública $-5^{\circ}$ lugar e governos municipais - $13^{\circ}$ lugar (INSTITUTO BRASILEIRO DE OPINIÃO PÚBLICA E ESTATÍSTICA, 2018).

Por conseguinte, considerando as informações geradas pelo diagnóstico participativo e com base nas diretrizes do PEAMMS, trilhamos na vertente de três desafios do campo de estudo. Assim, previamente às intervenções, desenvolvemos ações de mobilização social que se constituíram de etapas de socialização do diagnóstico com a comunidade, buscando esclarecer o que já foi realizado e os problemas a serem enfrentados. 
Para tanto, distribuímos em todas as residências e estabelecimentos comerciais da comunidade um informativo elencando os principais pontos do diagnóstico; realizamos encontros dentro da escola, com participação de professores e alunos, para compartilhar os dados e discutir os problemas identificados; divulgamos as informações junto aos fiéis da igreja, por intermédio do líder religioso local e; participamos de um seminário organizado pela prefeitura municipal com objetivo de mostrar a importância dos enfrentamentos.

A partir desse processo intencional, criamos uma rede de cooperação mútua envolvendo os atores sociais que mais se destacaram no processo investigativo: moradores da comunidade, escola, igreja, secretaria municipal de meio ambiente, secretaria municipal de educação, universidade, cooperativa de recolhedores de material reciclável, organização não governamental. Juntos, planejamos e desenvolvemos propostas de intervenção social, que configuraram as ações de enfrentamento socioambiental no campo de estudo, com o propósito de atender as prioridades identificadas no cenário.

Neste artigo, descrevemos e discutimos os resultados dessas etapas participantes, que abordaram os seguintes temas: a educação ambiental na escola, a gestão dos resíduos eletrônicos na comunidade, e a elaboração de políticas públicas por meio de um programa socioambiental do município.

\section{Enfrentamento1: Ações de educação ambiental no espaço escolar}

O bom nível de interatividade entre a escola e a comunidade foi decisivo para que aprofundássemos a investigação no espaço escolar. Assim, após autorizações da Secretaria Municipal de Educação e da direção da escola, buscamos conhecer as abordagens educativas relacionadas à educação ambiental por meio de análise documental, observações de campo e participação com grupos de trabalho.

\section{[...] o interesse superficial e a} escassez de apoio legítimo do poder público causam

fragmentação de esforços e reduz o potencial de articulação em rede, constituindo-se de elementos impeditivos para o sucesso dos enfrentamentos $[. .$.

Nos documentos analisados, observamos que a escola apresentava em seu Projeto Político Pedagógico (PPP) a busca por melhorias na sua infraestrutura e propostas de práticas educativas em jornada ampliada com dois grupos de lideranças denominados Agentes Ambientais e Jovens Empreendedores. Aproximamos desses dois grupos de trabalho e percebemos que as atividades por eles desenvolvidas não relacionavam entre si e nem mesmo com as necessidades da comunidade local, assim como não efetivavam transformações mais significativas no contexto da própria escola. Ademais, de acordo a coordenação dos grupos, era alto o índice de evasão dos alunos durante o ano letivo.

A partir dessas informações e em consonância com a proposta de intervenção acordada com a direção, estabelecemos etapas de planejamento e de implementação de algumas ações na escola, por meio de encontros dialogados com os dois grupos de liderança. Em Novaes e Gil (2009), temos que a técnica participativa no processo de investigação além de fazer parte do esforço para gerar informações relevantes para a pesquisa, confere ao pesquisador a condição de estar mais comprometido com as propostas transformadoras da realidade que se examina.

Desta feita, realizamos quatro encontros com os alunos, quando compartilhamos os resultados do diagnóstico participativo realizado na comunidade ao entorno e destacamos algumas diretrizes do projeto pedagógico da escola correlacionadas à missão dos grupos de lideranças. Realizamos, ainda nesse período, uma pesquisa interna para conhecer a percepção ambiental dos alunos do ensino fundamental, com uso de um questionário com sete questões objetivas em uma amostra de 150 estudantes do $4^{\circ}$ ao $9^{\circ}$ ano. Conforme resultados apresentados nos Gráficos 1 e 2, aproximadamente $80 \%$ dos estudantes entendem que cuidar da escola é responsabilidade de todos, e não apenas da direção ou das autoridades públicas. Da mesma forma, foi possível verificar bom nível de conscientização ambiental dos alunos, no entanto eles ainda tendem a negligenciar atitudes relacionadas ao descarte de resíduos. 


\section{Grafico 1}

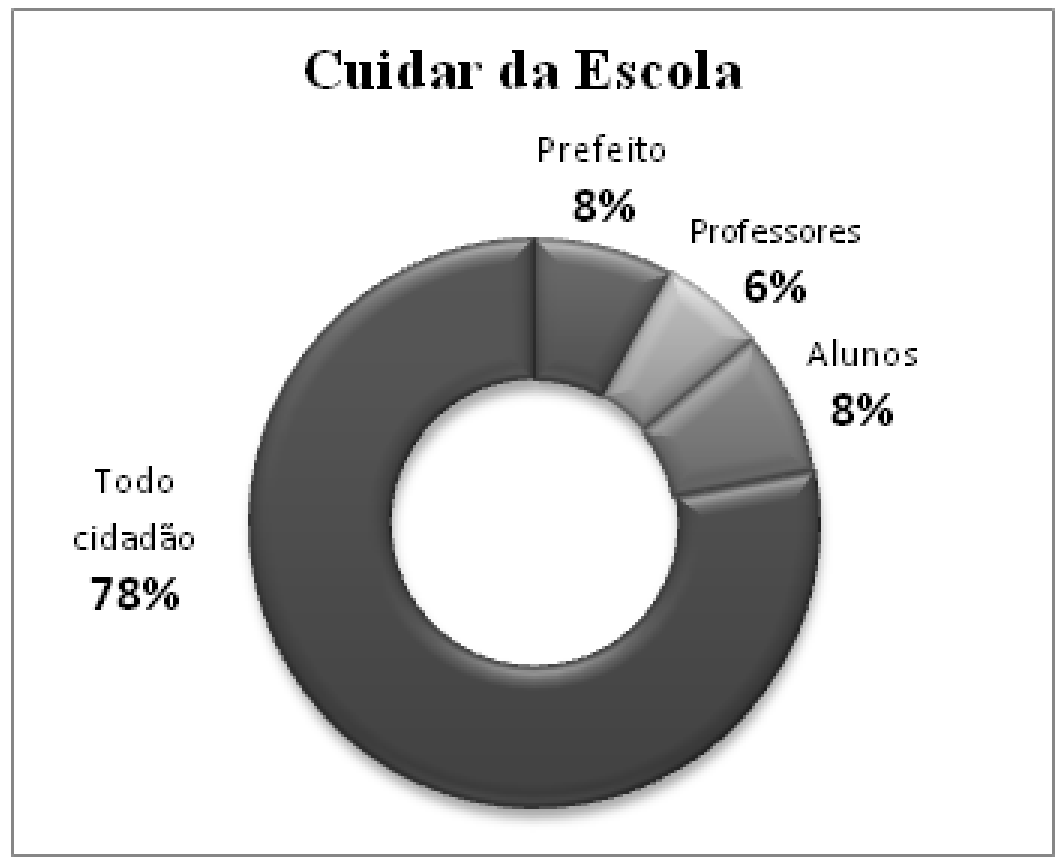

Fonte: Elaborado pelos autores (2019).

\section{Grafico 2}

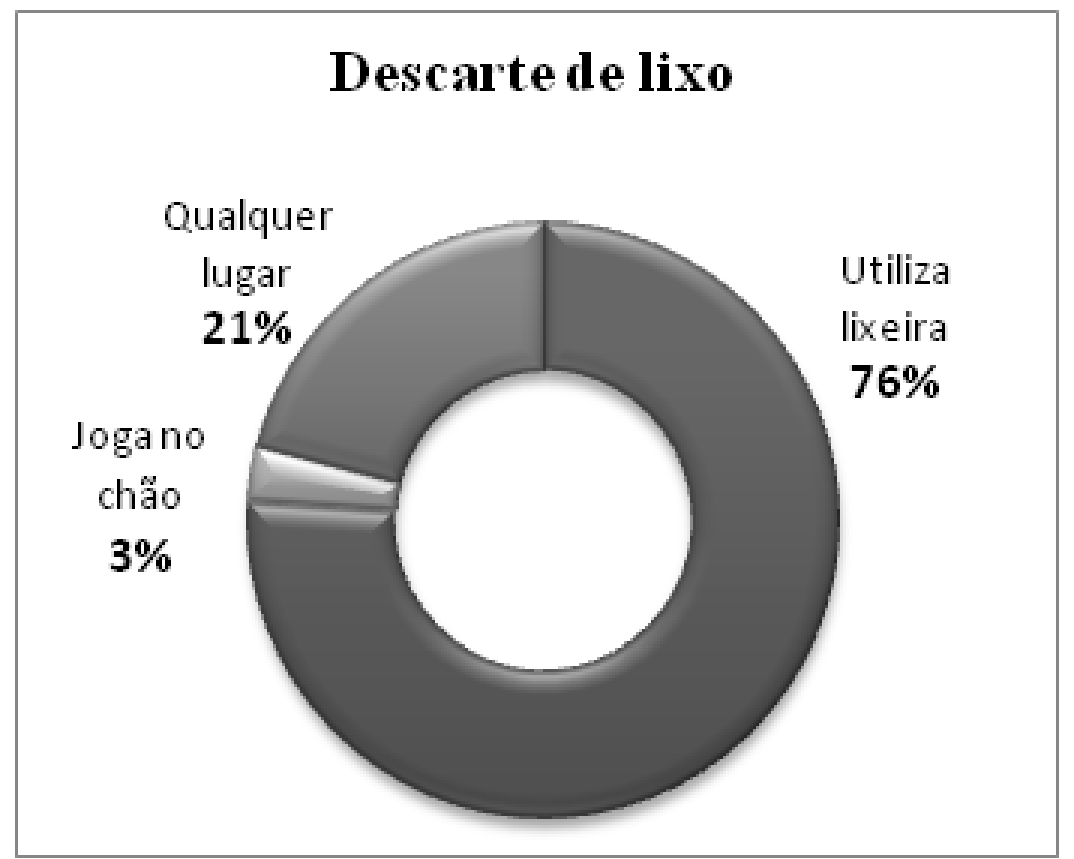

Fonte: Elaborado pelos autores (2019).

Concluídas as discussões com os grupos sobre os resultados do levantamento de dados, reunimos diretoria da escola, pedagogos, professores, inspetores, secretários, bibliotecários e pessoal da limpeza e da cozi- 
nha para enfatizar a importância de apoiar as ações dos grupos de liderança da escola. Por conseguinte, iniciamos o planejamento das ações socioambientais, com foco nas prioridades comunitária e escolar. Assim, seguimos a programação de reuniões semanais no contraturno das aulas regulares dos componentes dos grupos, realizamos encontros de aprendizagem, oficinas de prática, visitas técnicas e mostras.

Durante o período de quatro semestres desenvolvemos atividades de educação ambiental com os Agentes Ambientais e de empreendedorismo social com os Jovens Empreendedores, sempre buscando correlacionar as atividades dos dois grupos para mostrar a importância do trabalho em equipe e das parcerias nos enfrentamentos socioambientais.

Nos trabalhos de empreendedorismo social simulamos a criação de uma empresa com a missão de produzir bolsas e estojos a partir da reutilização de lonas descartadas, cujo público alvo era a comunidade escolar (alunos, professores, funcionários e pais). Nos encontros de aprendizagem discutimos temas como: plano de negócio, responsabilidade socioambiental (causas e consequências dos impactos sociais e ambientais), sustentabilidade financeira e nas oficinas de prática desenvolvemos etapas de limpeza, corte e costura dos materiais. Por meio de mostras, feiras e bazares os produtos geravam renda para investir no próprio projeto da escola, proporcionando condições para manter as atividades tanto da empresa simulada quanto dos Agentes Ambientais.

No plano de ação dos Agentes Ambientais seguimos as vertentes conservadora e crítica da educação ambiental. Loureiro (2005) abaliza que a concepção conservadora consiste em vivências práticas apoiadas em uma pedagogia centrada no comportamento humano, distanciando dos fatos sociais e políticos envolvidos, enquanto que a vertente crítica é direcionada para compreensão das relações em sociedade, contextualizando os fatos sociais às questões de cidadania, participação social na ciência e tecnologia e interesses públicos e privados. Nesse sentido, os Agentes Ambientais dedicaram-se inicialmente a ações estruturantes na escola, envolvendo criação de espaços para armazenamento de resíduos, instalação de coletores e comunicação visual para coleta seletiva, seguidas de atividades educativas envolvendo descarte, destinação e reciclagem. No segundo momento, os alunos participaram de reflexões críticas acerca da crise socioambiental, por meio de visitas técnicas a uma cooperativa de catadores, uma usina hidrelétrica e a uma universidade pública, combinadas com encontros dialogados para compartilhar as principais percepções.

Percebemos que essa experiência vivencial trouxe avanços para as discussões nos grupos, proporcionando aos alunos melhor compreensão sobre todas as ações desenvolvidas por eles na escola. Observamos também que a organização da intervenção, partindo de uma concepção conservadora e avançando gradativamente para uma reflexão crítica, contribuiu para construir uma relação mais próxima dos alunos com o meio ambiente, com as práticas desenvolvidas e, sobretudo, com as questões sociais envolvidas, despertando-os para novas possibilidades de aprendizagem sobre as causas e consequências dos problemas sociais e ambientais.

Julgamos importante destacar algumas fragmentações observadas em nossa análise. Durante as reflexões, vários alunos enfatizaram que não conversam em casa sobre os temas tratados durante nossos encontros, o que nos permite fazer uma leitura de que há uma lacuna de diálogo sobre a vida escolar nessas famílias. Por outro lado, dada atenção ao nível de maturidade dos alunos, verificamos aumento de interesse por parte do grupo quando tratamos de questões polêmicas da vida em sociedade, tais como: corrupção, violência, fome, desemprego, ciência e tecnologia, dentre outras, fato que revela o potencial observador e crítico dos alunos.

No tocante às limitações, citamos algumas dificuldades que encontramos durante a intervenção, com ressalva a questão de apoio financeiro, que desde o início dos trabalhos já havia sido pontuada pela direção como inexistente. Destacamos nossa percepção sobre o pouco envolvimento dos pais com o projeto, uma vez que, de três agendamentos de encontro logramos êxito apenas em um, o de encerramento. O transporte para realização das visitas técnicas também configurou-se como empecilho no andamento das atividades programadas, haja vista as dificuldades de atendimento por parte da prefeitura, ainda que a autorização e o agendamento houvessem ocorrido com grande antecedência e que se tratava de proposta da própria secretaria de educação, sugerida nas orientações de trabalho com os grupos.

Ademais, verificamos também que, embora as políticas de ensino busquem incluir os pressupostos da educação ambiental no ambiente escolar, o envolvimento das famílias e da própria comunidade com a escola ainda concentra-se em eventos pontuais, tais como: apresentações culturais e campanhas de arrecadação, que, não menos importantes, podem evoluir para uma parceria mais efetiva à medida que os projetos socioambientais da escola avancem de uma proposta estritamente pedagógica e conservadora para um patamar de engajamento social, envolvendo temas capazes de provocar novos debates acerca de problemas sociais e ambientais relevantes para a realidade da comunidade. 


\section{Enfrentamento 2: gestão participativa sobre os resíduos eletrônicos}

Ao considerarmos os indicadores do diagnóstico, o descarte de eletrônicos configurou-se como um problema relevante na comunidade, uma vez que são depositados nas calçadas e terrenos baldios, não havendo um serviço organizado para coleta desse tipo de material. Ao pontuarmos que esse desafio envolvia a comunidade como um todo, optamos pela formação de uma rede de atores sociais para atuação conjunta no enfrentamento da questão. Assim, reunimos e discutimos os resultados da pesquisa social com quatro instituições locais: duas escolas, uma organização não governamental e uma igreja.

A partir dessa mobilização e com base em princípios democráticos e participativos, estabelecemos um acordo com essas lideranças no intuito de organizar o enfrentamento do problema com os eletrônicos. Cada instituição parceira assumiu o compromisso de reservar um espaço apropriado para receber os resíduos eletrônicos descartados pelos moradores, bem como de realizar ampla divulgação junto a seu público. Assim, foram criados quatro pontos de entrega voluntária de descarte eletrônico e, para dar suporte ao trabalho coletivo, foram confeccionados e distribuídos calendários com orientações sobre a importância do descarte correto, indicando local e periodicidade da coleta na comunidade.

Fizemos o monitoramento da ação durante um ano e observamos que a igreja atingiu o melhor desempenho na coleta, tendo em vista o grande volume de material entregue. As escolas apresentaram bom índice de adesão do público, porém isso ocorreu somente na ocasião dos eventos pontuais por elas realizados, e a ONG não prosperou na coleta. Esses resultados ratificaram os apontamentos do diagnóstico participativo em relação à dimensão de interatividade dessas instituições com a comunidade, embora não tenha ocorrido interação entre as próprias instituições durante o processo.

\section{Enfrentamento 3: elaboração de políticas públicas socioambientais}

Na compreensão de que as políticas públicas constituem-se de instrumento para que o Estado possa organizar e atender as demandas da sociedade (SORRENTINO et al., 2005), esse estudo nos oportunizou participar de um seminário que reuniu gestores públicos, parlamentares, membros do ministério público, organizações não governamentais, representantes de movimentos sociais, associações de moradores, cooperativas, acadêmicos e docentes universitários para discutir problemas relevantes do panorama socioambiental do município, da região e do país.

Após o evento, integramos uma comissão vinculada à secretaria municipal de meio ambiente responsável pela criação de um programa socioambiental como parte das políticas públicas do município. Durante oito meses participamos da construção desse programa que, nos moldes de uma pesquisa participante, consistiu na terceira intervenção, agregando novas possibilidades de observação quanto à dinâmica de organização do poder público acerca dos enfrentamentos socioambientais.

No decorrer dessa ação, percebemos o empenho da equipe na busca de alternativas para conduzir as propostas priorizando a participação pública, o que apontava para uma intervenção promissora, uma vez que reunia demandas sociais, políticas públicas e modelo participativo. O planejamento participativo seguia fluxo normal até que surgiram os primeiros contratempos: as reuniões começaram a sofrer descontinuidade, o apoio administrativo que previa orçamento para as primeiras ações do programa foi suspenso, os trabalhos deixaram de avançar e o processo estagnou-se no final desse período. Tal cenário aproxima-se da observação de Jacobi (2003) ao salientar que as limitações das articulações no campo social são muitas vezes provenientes da forma como se estabelece o poder de decisão e, sobretudo, do próprio desinteresse da sociedade, que é derivado da descrença nos políticos e do descrédito repassado pelas instituições.

\section{Considerações finais}

Com base em nossas análises, a participação social nos processos de enfrentamento socioambiental requer uma liderança para mediar as demandas identificadas. Entretanto, essas lideranças nem sempre estão preparadas para conduzir as situações deflagradas, sobretudo, motivadas para dar continuidade às ações e efetivar transformações mais significativas na sociedade. Embora esses aspectos corroborem a capacidade de organização social na dinâmica de enfrentamento, é preciso reconhecer que os entraves mais expressivos emergem de um cenário caracterizado por interesses superficiais sobre o tema. Isso pode estar associado a lacunas que envolvem variáveis como: tempo, conhecimento, condições de trabalho, recursos humanos e financeiros. 
Na escola, acompanhamos as transformações derivadas de processos de mobilização integrados a um planejamento coletivo que despertou a comunidade escolar para novas possibilidades de abordar a educação ambiental. Nesse sentido, a escola firmou-se como espaço promissor para o diálogo socioambiental e propício para desenvolvimento do pensamento crítico acerca da crise socioambiental, ferramentas fundamentais para organização de uma sociedade consciente e apta para trilhar os enfrentamentos.

A tratativa dos resíduos eletrônicos superou nossas expectativas, pois, embora seja uma ação baseada na mudança de hábitos, configurou-se como tema potencial para aprofundamento de outros debates junto à comunidade, com vistas a consolidar outras reflexões críticas a partir do poder de comunicação e influência dos atores sociais envolvidos no enfrentamento.

$\mathrm{Na}$ aproximação com as políticas públicas, constatamos uma dicotomia teoria/prática que, de um lado enfatiza o interesse do poder público na promoção de ações de enfrentamento socioambiental, e de outro, revela intenções ainda carregadas de superficialidade e pouca valorização da participação pública, representada neste estudo por instituições, pesquisadores e membros da sociedade civil organizada.

Por fim, avaliamos que a sociedade detém capacidade de influência para constituir processos organizados de enfrentamento socioambiental por meio de seus atores sociais. Contudo, esse potencial não se pereniza de forma eficaz, tendo em vista que as ações ainda não se consolidam de forma plena na estrutura social. Sendo assim, concluímos que o poder de influência dos atores sociais que exercem liderança em suas comunidades é fator preponderante nas relações coletivas capaz de impulsionar avanços nos processos de enfrentamento socioambiental. Por outro lado, o interesse superficial e a escassez de apoio legítimo do poder público causam fragmentação de esforços e reduz o potencial de articulação em rede, constituindo-se de elementos impeditivos para o sucesso dos enfrentamentos, uma vez que desencadeiam abandono das ações e descrédito do assunto diante da população.

\section{Referências}

ALMEIDA, R.; SCATENA, L. M.; LUZ, M. S. Percepção ambiental e políticas públicas: dicotomia e desafios no desenvolvimento da cultura de sustentabilidade. Ambiente \& Sociedade, São Paulo, v. 20, n. 1, p. 43-64, 2017.

BECK, U. Risk Society: Towards a New Modernity. London: Sage, 1992.

BITTAR, M.; FERREIRA JÚNIOR, A. Ciência e Tecnologia: uma perspectiva histórico-filosófica. In: HAYASHI, M. C. P. I.; RIGOLIN, C. C. D.; KERBAUY, M. T. M. (org.). Sociologia da Ciência: contribuições ao campo CTS. Campinas, SP: Alínea, 2014. p. $13-40$.

BRASIL. Ministério das Cidades. Secretaria Nacional de Saneamento Ambiental. Programa de Educação Ambiental e Mobilização Social em Saneamento. Caderno Metodológico para ações de educação ambiental e mobilização social em saneamento. Brasília - DF: Ministério das Cidades, 2009.

BRASIL. Ministério do Meio Ambiente. Panorama nacional sobre gestão do lixo, destinação dos resíduos e logística reversa em estados e municípios. Out/2018. Disponível em: http://www.mma.gov.br/informma/item/15166-54-dos-munic\%C3\%ADpiost\%C3\%AAm-plano-de-res\%C3\%ADduos.html. Acesso em: 15 jun. 2019.

BRASIL. Lei n. 9.795 de 27 de abril de 1999. Dispõe sobre a educação ambiental, institui a Política Nacional de Educação Ambiental e dá outras providências. Disponível em: http://www.planalto.gov.br /ccivil_03/leis/19795.htm. Acesso em: 20 jun. 2019.

BRASIL. Programa de Educação Ambiental. Documento básico. Ministério do Meio Ambiente, Diretoria de Educação Ambiental: Ministério da Educação, Coordenação Geral da Educação Ambiental. 2. ed. Brasília, DF, 2003, 50p.

COSTA, C. A.; LOUREIRO, C. F. A interdisciplinaridade em Paulo Freire: aproximações político-pedagógicas para a educação ambiental. Katálysis, Florianópolis, v. 20, n. 1, p. 111-121, jan./abr. 2017.

COSTA, H. A.; BURSZTYN, M. A. A.; NASCIMENTO, E. P. do. Participação social em processos de avaliação ambiental estratégica. Sociedade e Estado, Brasília, v. 24, n. 1, p. 89-113, jan./abr. 2009.

FLEURY, L. C.; ALMEIDA, J.; PREMEBIDA, A. O ambiente como questão sociológica: conflitos ambientais em perspectiva. Sociologias, Porto Alegre; ano 16, n. 35, jan./abr. 2014, p 34-82.

GIDDENS, A. Risco, Confiança, Reflexividade. In: ULRICH, B.; GIDDENS, A.; LASH, S. (ed.). Modernização Reflexiva. São Paulo: Ed. da UNESP, 1997.

GREGOLIN, J. Â. R.; HOFFMANN, W. A. M.; FARIA, L. I. L. Aspectos metodológicos da prospecção tecnológica para a pesquisa em Ciência, Tecnologia e Sociedade. In: SOUZA, C. M.; HAYASHI, M. C. P. I. (org.). Ciência, Tecnologia e Sociedade: enfoques teóricos e aplicados. São Carlos: Pedro e João Editores, 2008. p. 89-112.

HADDAD, N. Metodologia de estudos em ciência da saúde: como planejar, analisar e apresentar um trabalho científico. São Paulo: Roca; 2004.

INSTITUTO BRASILEIRO DE OPINIÃO PÚBLICA E ESTATÍSTICA (IBOPE). Índice de confiança Social, IBOPE, 2018. Disponível em: http://www.ibopeinteligencia.com/noticias-e-pesquisas/confianca-do-brasileiro-nas-instituicoes-e-a-mais-baixa-desde2009/. Acesso em: 10 maio 2019. 
JACOBI, P. R. Espaços públicos e práticas participativas na gestão do meio ambiente no Brasil. Sociedade e Estado, Brasília, v.18, n. 1-2, p. 315-318, jan./dez. 2003.

LAYRARGUES, P. P.; LIMA, G. F. da C. As macrotendências político-pedagógicas da educação ambiental brasileira. Ambiente \& Sociedade, São Paulo, v. 17, n. 1, p. 23-40, jan./mar., 2014.

LOUREIRO, C. F. B. Complexidade e dialética: contribuições à práxis política e emancipatória em educação ambiental. Educação \& Sociedade [online], Campinas, 2005, v.26, n. 93, pp.1473-1494.

LOUREIRO, C. F. B.; LAYRARGUES, P. P. Ecologia política, justiça e educação ambiental crítica: perspectivas de aliança contrahegemônica. Trabalho, Educação e Saúde, Rio de Janeiro, v. 11, n. 1, p. 53-71, abr. 2013.

MARTINS, C. H. B. A sociedade de risco: visões sobre a iminência da crise ambiental global na teoria social contemporânea. Ensaios FEE, Porto Alegre, v. 25, n. 1, p. 233-248, abr. 2004.

MITCHAM, C. En busca de una nueva relacion entre ciencia, tecnologia y sociedad. In: MEDINA, M.; SANMARTÍN, J. (ed.). Ciencia, tecnología y sociedad: estudios interdisciplinares en la universidad, en la educación y en la gestión política y social. Barcelona: Anthropos, 1990. p. 11-19.

NEDER, R. T. Estudos CTS e Educação: por um novo regime de controvérsia científica. Linhas Críticas, Brasília, DF, v. 21, n. 45, p. 265-274, maio/ago. 2015.

NOVAES, M. B. C.; GIL, A. C. A pesquisa-ação participante como estratégia metodológica para o estudo do empreendedorismo social em administração de empresas. RAM: Revista de Administração Mackenzie, São Paulo, v. 10, n. 1, jan./fev. 2009.

ORGANIZAÇÃO DAS NAÇÕES UNIDAS (ONU). Transformando Nosso Mundo: AAgenda 2030 para o desenvolvimento Sustentável. Trad. Centro de Informação das Nações Unidas para o Brasil (UNIC Rio). Out/2015. Disponível em: https://nacoesunidas.org/pos2015/ agenda2030/. Acesso em: 16 fev. 2018.

ROTHBERG, D.; KERBAUY, M. T. M. A relevância da teoria da sociedade de risco para os estudos sociais de ciência e tecnologia. In: HAYASHI, M. C. P. I.; RIGOLIN, C. C. D.; KERBAUY, M. T. M. (org.). Sociologia da Ciência: contribuições ao campo CTS. Campinas, SP: Alínea, 2014. p. 239-266.

SORRENTINO, M.; MENDONÇA, R. T. P.; FERRARO JÚNIOR, L. A. Educação ambiental como política pública. Educação $e$ Pesquisa, São Paulo, v. 31, n. 2, p. 285-299, maio/ago. 2005.

SOUZA, C. A nova gestão pública. In: Gestão pública: desafios e perspectivas. Salvador: Fundação Luís Eduardo Magalhães, 2001. p. 38-62.

\section{Ricardo Almeida}

ricalmeida1212@gmail.com

Doutor em Ciência, Tecnologia e Sociedade (CTS) pela Universidade Federal de São Carlos (UFSCar) Analista em Gestão de Pessoas da Universidade Federal do Triângulo Mineiro (UFTM)

\section{UFTM}

Av. Madre Maria José, 122 - Abadia

Uberaba-MG-Brasil

CEP: 38025-100:

\section{Carlos Roberto Massao Hayashi}

massao@ufscar.br

Doutor em Educação pela Universidade Federal de São Carlos (UFSCar)

Professor do Programa de Pós-Graduação em Ciência, Tecnologia e Sociedade da Universidade Federal de São Carlos (UFSCar)

\section{UFSCar}

Rod. Washington Luiz, s/n

São Carlos - SP - Brasil

CEP: $13565-905$

\section{Agradecimentos}

A todos os professores do Programa de Pós-Graduação em Ciência, Tecnologia e Sociedade da UFSCar que compartilham seus conheci- mentos e estimulam seus alunos a esperançar. Aos participantes da pesquisa-ação que contribuíram com este estudo, expressando suas percepções e seus anseios por transformações sociais positivas. 


\section{Agência financiadora}

Não se aplica.

\section{Contribuições dos autores}

Ricardo Almeida delineou a pesquisa, coletou os dados, tabulou e analisou os resultados e redigiu o artigo. Carlos Roberto Massao Hayashi orientou a pesquisa, participou da discussão dos resultados e da revisão do artigo. Ambos os autores aprovaram a versão final do texto
Aprovação por Comitê de Ética e consentimento para participação

O projeto de pesquisa foi aprovado pelo Comitê de Ética em Pesquisa envolvendo seres humanos (CAAE: $63715516,4,0000,5154)$. Os sujeitos de pesquisa expressaram consentimento de participação em documento próprio.

Consentimento para publicação

Consentimento dos autores.

\section{Conflito de interesses}

Não há conflito de interesses. 